\title{
REVISÃO NARRATIVA SOBRE A HUMANIZAÇÃO DA ASSISTÊNCIA PELA EQUIPE DE ENFERMAGEM NA ÁREA ONCOLÓGICA ${ }^{i}$
}

\section{NARRATIVE REVIEW ON THE ASSISTANCE OF HUMANIZATION NURSING TEAM IN THE AREA ONCOLOGIC}

\section{REVISIÓN NARRATIVA SOBRE LA ASISTENCIA DE ENFERMERÍA HUMANIZACION EQUIPO EN EL ÁREA ONCOLÓGICA}

Miriam Lopes; Ana Cláudia Silva ${ }^{1}$; Angélica Maria Ferreira $^{3}$; Aline Aparecida Costa Faria Lino ${ }^{4}$

\section{RESUMO}

Objetivo: Identificar e problematizar as publicações científicas nacionais acerca da humanização da assistência pela equipe de enfermagem na área oncológica. Método: Revisão narrativa da leitura a partir de pesquisa eletrônica de artigos indexados na SciELO, BVS e Portal Capes com os descritores "humanização da assistência", "enfermagem" e "oncologia", publicados em português e disponíveis na íntegra, compreendidos no período de 2003 a 2013. Resultados: Os

\footnotetext{
${ }^{1}$ Enfermeira. Especialista em Enfermagem em Oncologia. Mestre em Ciências Doutoranda pelo Programa de PósGraduação em Enfermagem Fundamental (EERP/USP). Professor visitante no curso de Pós-Graduação em Oncologia pelo Instituto ENAF - FMG e orientadora do TCC, Poços de Caldas/MG. E-mail: mi.lops@ @otmail.com

${ }^{2}$ Enfermeira. Especialista em enfermagem em Oncologia, pelo Instituto ENAF - FMG, Poços de Caldas/MG, Enfermeira Geral no Hospital Santa Casa de Misericórdia de Muzambinho -MG. $\quad$ Brasil. ana.estarbem@yahoo.com.br

${ }^{3}$ Enfermeira. Especialista em enfermagem em Oncologia, pelo Instituto ENAF - FMG, Poços de Caldas/MG. Enfermeira Assistencial na Santa Casa de Misericórdia do município de Guaxupé/MG, Brasil. E-mail: angelfer2010@ hotmail.com

${ }^{4}$ Enfermeira. Especialista em enfermagem em Oncologia, pelo Instituto ENAF - FMG, Poços de Caldas/MG, Brasil. E-mail: aacflcrc@hotmail.com
}

resultados apontam que a humanização junto ao cliente inicia desde sua admissão na instituição com o acolhimento. Entretanto, existem alguns desafios e dificuldades na efetividade da humanização, muitas vezes, o profissional passa a realizar seu trabalho de maneira mecanizada, o qual deixa de lado os sentimentos e as necessidades do paciente. Porém, as estratégias para o cuidado humanizado se baseiam em atitudes que favoreça a expressão e a valorização dos sentimentos dos pacientes, para que seja possível identificar prováveis áreas problemáticas, além da compreensão de suas necessidades. Conclusão: Dessa maneira, embora exista política sobre a humanização da assistência, na prática verificamos que a humanização pela equipe de enfermagem ainda se concentra em determinadas áreas em detrimento de outras, tais como: cuidados paliativos, assistência à criança oncológica, ou seja, à grupos de indivíduos considerados vulneráveis. 
Portanto, a enfermagem deve estar sempre trabalhando no processo de humanizar o cuidado. No entanto, para a humanização acontecer, não depende apenas da boa vontade da equipe, mas também da aceitação do paciente e seus familiares.

Descritores: Humanização da assistência; Enfermagem; Oncologia.

\section{ABSTRACT}

Objective: Identify and discuss national scientific publications about the humanization of care by nursing staff in oncology. Methods: Narrative review of reading from an electronic search of articles indexed in SciELO, BVS and Capes Portal with the descriptors "humanization", "nursing" and "oncology", published in Portuguese and available in its entirety comprised in the period from 2003 to 2013.

Results: The results indicate that the humanization begins with the client since his admission to the institution with the host. However, there are some challenges and difficulties in the effectiveness of humanization often, the professional shall perform their work in a mechanized manner, which leaves aside the feelings and needs of the patient. However, strategies for humanized care are based on attitudes that favor the expression and recovery of patients' feelings, so that you can identify potential problem areas, beyond the understanding of their needs. Conclusion: Thus, although there policy on humanization in practice we find that the humanization by nursing staff is still concentrated in certain areas over others, such as palliative care, oncology care to the child, in other words, the groups individuals considered vulnerable. Therefore, nursing should always be working to humanize the care process. However, for humanizing happen, does not depend solely on the goodwill of staff, but also the acceptance of patients and their families.

Descriptors: Humanization of assistance; Nursing; Oncology.

\section{RESUMEN}

Objetivo: Identificar y analizar las publicaciones científicas nacionales acerca de la humanización por parte del personal de enfermería en oncología. Métodos: Revisión narrativa de la lectura de una búsqueda electrónica de artículos indexados en SciELO, BVS y Capes Portal con los descriptores "humanización", "enfermería" y 
"oncología", publicado en portugués y disponible en su totalidad en el período de 2003 a 2013. Resultados: Los resultados indican que la humanización comienza con el cliente desde su ingreso a la institución con el host. Sin embargo, hay algunos retos $\mathrm{y}$ dificultades en la eficacia de la humanización menudo, el profesional deberá realizar su trabajo de manera mecanizada, lo que deja a un lado los sentimientos y las necesidades del paciente. Sin embargo, las estrategias para el cuidado humanizado se basan en las actitudes que favorecen la expresión y la recuperación de los sentimientos de los pacientes, de manera que pueda identificar las áreas potenciales de problemas, más allá de la comprensión de sus necesidades. Conclusión: Por lo tanto, aunque la política de humanización en la práctica nos encontramos con que la humanización por el personal de enfermería aún está concentrada en ciertas áreas sobre las que otros, como los cuidados paliativos, la atención oncológica para el niño, es decir, los grupos personas consideradas vulnerables. Por lo tanto, la enfermería debe estar siempre trabajando para humanizar el proceso de atención. Sin embargo, para humanizar suceda, no depende únicamente de la buena voluntad del personal, sino también la aceptación de los pacientes y sus familias.

Descriptores: Humanización de la atención; Enfermería; Oncología.

\section{INTRODUÇÃO}

Apesar dos os recursos tecnológicos estarem, positivamente, presentes no cotidiano da assistência ao paciente a fim de propiciar-lhes maior suporte, principalemente à pacientes hospitalizados, a assistência de enfermagem não deve ser automatizada. Pois os indivíduos necessitam não só da assistência física, mas também do emocional e espiritual $^{(1)}$.

Diante desse contexto, a assistência ao paciente oncológico mostra-se complexa, visto que é necessário considerar diversas dimensões, dentre eles os físicos, psicológicos, espiritual, culturais, sociais e econômicos, além dos pré conceitos e mitos existentes perante a palavra "câncer", a qual é repleta de significados como maldição e morte ${ }^{(2)}$. Assim, o enfermeiro apresenta papel fundamental nas ações de prevenção primária e secundária no controle do câncer, cujas competências referem-se à 
assistência a pacientes com câncer na avaliação diagnóstica, tratamento, reabilitação e atendimento aos familiares, podendo inclusive desenvolver ações educativas e integradas com outros profissionais, apoiar medidas legislativas e identificar fatores de riscos ocupacionais para a prática da enfermagem na assistência ao paciente oncológico e sua família ${ }^{(3)}$.

Nessa perspectiva, a integralidade da assistência de enfermagem ao paciente oncológico requer uma prática humanizada, na qual a equipe deve estar ciente das dificuldades e desafios a serem transpostos e buscar, junto aos atores envolvidos no processo saúdedoença, estratégias de enfrentamento. Desta maneira, a humanização ressurge para valorizar as características do ser humano.

Com tudo, o interesse pela realização desse estudo deve-se ao fato de que, apesar dos avanços da medicina e tecnológicos para detecção precoce e possibilidades de tratamento, o câncer continua sendo uma enfermidade temida, repleta de crenças pela sociedade, a qual, muitas vezes, não se constitui em uma doença relacionada à sexo, cor, classe social ou religião. Como é uma doença carregada de crenças e mitos, além de estar associada à sofrimento e finitude da vida, como não se sensibilizar com os pacientes oncológicos e seus familiares? Afinal de contas, hoje cuidamos destes pacientes acometidos pelo câncer; amanhã, poderá ser qualquer um de nós. E de que maneira você gostaria que os profissionais prestassem a assistência, seja à você ou à um familiar?

\section{OBJETIVO}

Identificar as publicações científicas nacionais acerca da humanização da assistência pela equipe de enfermagem na área oncológica, compreendidos no período de 2003 a 2013 e caracterizar os estudos quanto aos autores, título do artigo, periódico e ano da publicação em relação às bases de dados e/ou bibliotecas virtuais pesquisadas a fim de analisar a maneira como esta temática vem sendo trabalhada no âmbito da enfermagem oncológica brasileira.

\section{REFERENCIAL TEÓRICO}

Com o intuito de melhorar a qualidade e a eficácia dos serviços prestados pelas instituições públicas do Brasil e modificar o padrão da assistência aos usuários atendidos nestas 
instituições, o Ministério da Saúde, por meio da Portaria no881/GM de 2001, institui o Programa Nacional de Humanização da Assistência Hospitalar (PNHAH), o qual visa aprimorar as relações entre profissionais de saúde e usuários, dos profissionais entre si e do hospital com a comunidade ${ }^{(4)}$. Posteriormente, lançou a Política Nacional de Humanização HumanizaSUS, cujos princípios são a valorização da dimensão subjetiva e social de todas as práticas de atenção e gestão; estimular a produção de saúde e de sujeitos; fortalecer o trabalho em equipe multiprofissional; atuar em rede de modo cooperativo e solidário; utilizar a informação e comunicação na construção de autonomia e protagonismo de atores envolvidos ${ }^{(5)}$. Portanto, humanizar é oferecer atendimento de qualidade articulando os avanços tecnológicos com acolhimento, com melhoria dos ambientes da assistência e das condições de trabalho dos profissionais ${ }^{(5)}$. Assim, humanização é procurar resgatar o respeito a vida humana, é aceitar que o seu paciente é um ser complexo, com sentimentos, dor, dúvidas, medo, insegurança e que leva consigo toda uma cultura e suas próprias crenças ${ }^{(6)}$.

\section{MATERIAL E MÉTODO}

Trata-se de uma revisão narrativa da literatura, uma vez que revisões de literatura possuem a finalidade de reunir conhecimentos sobre determinado assunto, além de sintetizar e resumir uma gama de publicações científicas, as quais proporcionam aos leitores a compreensão atual sobre a temática. Em termos narrativos, permite que determinado assunto seja descrito sob o ponto de vista teórico ou contextual ${ }^{(7)}$.

O levantamento de artigos científicos foi realizado a partir de pesquisa eletrônica em sítios com acesso público tais como nas bibliotecas virtuais: SciELO Brasil (Scientific Electronic Library Online), BVS (Biblioteca Virtual em Saúde, a qual engloba a base de dados LILACS, BDENF dentre outras) e Portal de Periódicos da Capes.

O acesso ocorreu entre os dias 06 e 07 de agosto de 2013. Os descritores utilizados para o levantamento dos artigos, de acordo com os Descritores em Ciências da Saúde (DeCS), foram: "humanização da assistência” e “enfermagem" e “oncologia” por meio do campo "todos os índices" na SciELO Brasil, sendo encontrados 2 artigos; na BVS por meio do campo "título, 
resumo, assunto", foram encontrados 28 trabalhos, entre as bases de dados LILACS e BDENF; e, no Portal Periódicos CAPES, por meio do campo "qualquer", foram encontrados 4 artigos.

Para a inclusão dos artigos determinou-se como parâmetros limitadores da busca inicial: pesquisa em sítios eletrônicos de acesso público, artigos no idioma português, disponíveis online e na íntegra, compreendidos no período de 2003 a 2013. Foram excluídas as publicações que não estivessem em formato de artigo científico como teses, editoriais, debates e resenhas. Optamos por esta escolha por considerar que muitos destes estudos, podem não terem sido submetidos a um rigoroso processo de avaliação, uma vez que esta revisão, realizada por pares, garante a qualidade do artigo e a observância quanto ao rigor metodológico científico.

Após levantamento preliminar nos sítios eletrônicos escolhidos, foram realizadas leituras dos títulos e resumos dos artigos a fim de refiná-los para a composição final deste estudo. Nesta etapa, além de considerar os critérios de inclusão, foram excluídos da amostra os artigos repetidos em mais de um sítio e os que não se relacionavam à temática. Desta maneira, foram selecionados estudos que problematizaram a humanização da assistência pela equipe de enfermagem na área oncológica, os quais 2 da SciELO, 6 artigos foram da BVS. Ressalta-se que no levantamento por meio da BVS surgiram apenas artigos oriundos das bases de dados LILACS e BDENF; e no Portal Capes, ou os artigos se repetiram em outras bases ou não se relacionavam à temática.

\section{RESULTADOS E DISCUSSÕES}

A caracterização dos dados quanto ao sítio eletrônico pesquisado: Scientific Electronic Library Online e Biblioteca Virtual de Saúde, segue abaixo (Quadro 1). 
QUADRO 1 - Caracterização dos estudos quanto aos autores, título, periódico e ano da publicação em relação à SciELO e BVS, compreendidos no período de 2003 a 2013. Poços de Caldas/MG, Brasil.

\begin{tabular}{|c|c|c|c|}
\hline Autores & Título & Periódico & Ano \\
\hline \multicolumn{4}{|c|}{ SciELO } \\
\hline $\begin{array}{l}\text { Siqueira; Barbosa; } \\
\text { Boemer }\end{array}$ & $\begin{array}{l}\text { O vivenciar a situação de ser com câncer: } \\
\text { alguns des-velamentos }\end{array}$ & $\begin{array}{l}\text { Revista Latino-americana de } \\
\text { Enfermagem }\end{array}$ & 2007 \\
\hline Duarte; Noro & $\begin{array}{l}\text { Humanização: uma leitura a partir da } \\
\text { compreensão dos profissionais da enfermagem }\end{array}$ & Revista Gaúcha de Enfermagem & 2010 \\
\hline \multicolumn{4}{|c|}{ BVS } \\
\hline $\begin{array}{l}\text { Costa; Lunardi Filho; } \\
\text { Soares }\end{array}$ & $\begin{array}{l}\text { Assistência humanizada ao cliente oncológico: } \\
\text { reflexões junto à equipe }\end{array}$ & $\begin{array}{l}\text { Revista Brasileira de } \\
\text { Enfermagem }\end{array}$ & 2003 \\
\hline Brito; Carvalho & $\begin{array}{l}\text { A humanização segundo pacientes oncológicos } \\
\text { com longo período de internação }\end{array}$ & Einstein & 2010 \\
\hline Gomes; Reis; Collet & $\begin{array}{l}\text { Gerenciando o cuidado de enfermagem no } \\
\text { ambulatório de quimioterapia pediátrica }\end{array}$ & Revista de Enferm UFPE on line & 2010 \\
\hline Silva; Moreira & $\begin{array}{l}\text { Desafios à sistematização da assistência de } \\
\text { enfermagem em cuidados paliativos } \\
\text { oncológicos: uma perspectiva da complexidade }\end{array}$ & $\begin{array}{l}\text { Revista Eletrônica de } \\
\text { Enfermagem }\end{array}$ & 2010 \\
\hline Maranhão et al. & $\begin{array}{l}\text { A humanização no cuidar da criança portadora } \\
\text { de câncer: fatores limitantes e facilitadores }\end{array}$ & $\begin{array}{l}\text { Joumal of the Health Sciences } \\
\text { Institute }\end{array}$ & 2011 \\
\hline Sales et al. & $\begin{array}{l}\text { Cuidado de enfermagem oncológico na ótica do } \\
\text { cuidador familiar no contexto hospitalar }\end{array}$ & Acta Paulista de Enfermagem & 2012 \\
\hline
\end{tabular}

Neste levantamento bibliográfico, é interessante observar que uma temática como esta, a qual abrange a humanização da assistência aos pacientes oncológicos, as publicações são, na sua maioria, realizadas em periódicos da área da enfermagem. Por mais que esta seja a profissão baseada no cuidar e que permanece em tempo integral junto aos pacientes, seja em processos de internação, tratamentos, reabilitação; a humanização não se limita aos profissionais dessa área, mas é um trabalho multidisciplinar e interdisciplinar.
Em relação às profissões dos autores e demais colaboradores, neste estudo foram encontrados um autor da área de educação física, um não havia especificação e a grande parcela eram enfermeiros. Para a obtenção destas informações foram consideradas as notas de rodapé informadas no corpo do artigo e consulta aos respectivos currículos na Plataforma Lattes.

Os dados foram sintetizados e categorizados nos seguintes temas: 1) A humanização junto ao cliente; 2) Desafios e dificuldades na efetividade da humanização; 3) Estratégias para o cuidado humanizado. 


\section{1) A humanização junto ao cliente}

O trabalho da enfermagem, ou seja, a assistência de enfermagem junto aos pacientes inicia-se desde sua admissão na instituição com o acolhimento, sendo a assistência direta a atividade principal e, as atividades administrativas, sistema de informação, educativas, científicas e humanizadas referentes às atividades que favorecem o cuidado qualificado ${ }^{(8)}$. Assim, como mencionado anteriormente, a assistência e/ou o cuidado constitui-se na essência da enfermagem, o qual compete ao enfermeiro reconhecer as peculiaridades de cada pessoa por ele atendida e adaptar o cuidado ${ }^{(9)}$, ou seja, fornecer um cuidado individualizado, integral e humanizado.

O câncer é uma doença crônica repleta de estigmas, no qual seu diagnóstico, mesmo nos dias atuais, é percebido e entendido pela maioria da população como uma espécie de "condenação" definitiva ${ }^{(8)}$. Em contrapartida, devido às inovações e avanços tecnológicos em saúde, sejam elas leve, leve-dura ou dura ${ }^{(10)}$, as possibilidades de diagnóstico, tratamento e um bom prognóstico são promissoras. Esta informação também é compartilhada por outros autores ${ }^{(8)}$, os quais afirmam que a cura em oncologia tem sido uma realidade cada vez mais frequente, principalmente nos cânceres infantis.

Desta forma, as mudanças dos hábitos de vida e da imagem corporal devido aos tratamentos antineoplásicos, a necessidade de deixar de fazer o que proporciona prazer pela vida e a impossibilidade de trabalhar, são dificuldades relatados por pacientes oncológicos, cujas dificuldades têm como consequência uma exclusão do convívio social $^{(11)}$.

E, pensando nestes aspectos de perda para os indivíduos diante de uma neoplasia e sua exclusão da sociedade, a enfermagem, a partir de um processo reflexivo sobre sua assistência, deve priorizar um acolhimento adequado e uma humanização da assistência qualificada.

Nesse sentido, a partir de uma análise quali-quantitativa com o intuito de identificar o conceito de humanização sob a perspectiva dos pacientes, um estudo ${ }^{(9)}$ identificou que a humanização, segundo os entrevistados, depende da interação com o profissional e da capacidade do profissional de fazer o paciente se sentir parte do processo, assim como as características pessoais influenciam na humanização, uma vez que compreende-se o cuidado como uma atitude imparcial, sem julgamentos 
e que, portanto, se traduz pelo respeito ao paciente, à sua individualidade, à sua intimidade, ao seu espaço e às suas crenças e valores. De acordo com esta mesma pesquisa, o apoio e força no momento de dificuldade nas vidas dos pacientes pode se tornar um diferencial no tratamento, além de minimizar o negativismo do dia-a-dia na unidade hospitalar.

Além disso, em situações como a hospitalização da criança para tratamentos oncológicos, os objetivos da assistência devem ser centrados na família, uma vez que a presença ativa da família e o envolvimento da criança, principalmente da mãe, é de grande relevância, pois são peças-chave capazes de facilitar todo o processo que envolve este cuidar ${ }^{(8,12)}$. A participação da família no ambiente hospitalar também ajuda na redução do tempo de internação, a enfrentar o medo e o terror do tratamento, de forma que as situações e rotinas vivenciadas no período de internação acabam se tornando mais compreendidas $\mathrm{e}$ aceitáveis, o que culmina na inserção da criança como agente participante do seu próprio cuidado $^{(8,12)}$. Numa outra vertente, a hospitalização pode gerar dificuldades como separação dos membros da família durante as internações, possível desajuste financeiro e sentimentos como angústia, dor, sofrimento e medo constante da possibilidade de morte, sendo que todos esses problemas podem levar ao rompimento da estrutura familiar ${ }^{(8)}$. Diante desse contexto, a inclusão da família na assistência não desconsidera toda a sistematização construída até o momento, mas a amplia e capacita a equipe de enfermagem para compreender o indivíduo de forma integral e a prestar uma assistência que ultrapasse as barreiras do atendimento tecnicista $^{(12)}$.

Apesar de determinada pesquisa ${ }^{(8)}$ afirmar que as ações do enfermeiro, diante de um ambulatório de quimioterapia infantil, devem ser dinâmicas para que se possa proporcionar um cuidado de qualidade, integral e humanizado à criança e sua família, salienta-se que essas considerações podem se estender à todos os âmbitos nos quais o enfermeiro e a enfermagem se faz presente.

Outro estudo ${ }^{(13)}$, por meio de abordagem qualitativa, constataram que as práticas humanizadas empregadas pelos profissionais podem ser diversas, mas a disponibilidade dos mesmos em realizá-las foi mais marcante, apesar da existência das dificuldades. Segundo a percepção dos profissionais participantes do estudo, a humanização 
do cuidado pode ser realizada mesmo na ausência de condições adequadas, uma vez que a viabilização dos meios para alcançá-la se faz individualmente.

Com isso, torna-se fundamental a interação entre o paciente e a equipe de enfermagem para que se estabeleça e valorize um vínculo afetivo e de confiança ${ }^{(9,12)}$, a fim de promover o cuidado do outro com qualidade, uma vez que a partir de uma escuta ativa do cuidador $^{(9,13)}$, há uma compreensão e valorização das ideias do paciente, cuja confiança adquirida possibilita a tomada de consciência de suas emoções, tornando um cuidado adequado $\mathrm{e}$ melhorando a adesão ao tratamento. Portanto, o carinho, a simpatia, a compreensão do momento em que os pacientes se encontram, o respeito e a qualidade no atendimento são fatores que facilitam a humanização da assistência. Por outro lado, temos que o mau humor dos profissionais, o barulho, a interrupção do sono e o excesso de idas ao quarto do paciente constituem nos fatores negativos relatados pelos pacientes $^{(9)}$.

Desta forma, cabe ao profissional de enfermagem, assumir um comportamento humanizado, ou seja, considerar o ser humano como indivíduo que pertence à sociedade, dotado de conhecimento, espiritualidade, cultura e sentimento. Isso significa tratar a pessoa que está sob cuidados com respeito, por meio de valores éticos, a fim de garantir sua individualidade e condição de sujeito social $^{(2,9,13)}$.

\section{2) Desafios e dificuldades na} efetividade da humanização

A base filosófica dos cuidados paliativos defende os valores que prezam pela qualidade de vida, a bioética, a abordagem humanista e o processo de morrer como natural e parte do ciclo da vida. Para tal, nesse modelo há prioridade do cuidar sobre o curar, da valorização da comunicação, da espiritualidade e do apoio ao luto, além do trabalho interdisciplinar ${ }^{(14)}$.

A humanização é um processo amplo, demorado e complexo, o qual é compreendido e recebido com resistência, pois envolve mudanças de atitudes, pensamentos comportamentos que geram insegurança quanto às incertezas futuras ${ }^{(2)}$.

A constante busca pela excelência da assistência ao paciente enfermo culminou no surgimento do principal desafio da enfermagem: o incessante aprimoramento do cuidado especializado e das técnicas baseadas em preceitos humanistas ${ }^{(12)}$. O cuidado 
está inteiramente ligado ao profissional que o executa, seu estado psicológico, físico e mental. Assim, o cansaço físico e a escassez de funcionários podem ser fatores desfavoráveis para executar essa prática $^{(9)}$.

Instigados na busca por compreender o processo de humanização na práxis da enfermagem mediante, a priori, da observação da dificuldade pela equipe de enfermagem em desempenhar um cuidado que atendesse às necessidades humanas dos pacientes internados, pesquisadores ${ }^{(13)}$, por meio de uma abordagem qualitativa, identificaram que um dos fatores para a efetiva humanização das suas práticas se concentra na questão das relações humanas no ambiente de trabalho devido a existência de profissionais que carecem de conhecimentos e preparo para realizar um trabalho multidisciplinar e humanístico. Por outro lado, outros pesquisadores ${ }^{(9)}$ acrescentam que, muitas vezes, o profissional passa a realizar seu trabalho de maneira mecanizada, o qual deixa de lado os sentimentos e as necessidades do paciente e que acaba por não respeitar os momentos individuais, como o sono e a dor; dificultando, assim, o relacionamento entre ambos.

De acordo com a percepção de profissionais, um dos aspectos negativos que dificulta a humanização da assistência hospitalar foram o mau humor dos funcionários, a demora em serem atendidos, níveis elevados de ruídos nos posto de enfermagem, interrupção durante o momento do sono, os quais são considerados por eles primordiais para a recuperação dos $\operatorname{adoecidos}^{(9)}$.

Sob outra vertente, a estrutura do hospital foi considerada uma limitação à humanização quando se considera um grupo de pacientes específicos como o infantil, pois uma estrutura hospitalar que não ofereça um ambiente infantil e aconchegante, é passível de que as crianças tornem-se apreensivas e pouco à vontade ao chegarem para a realização do tratamento. Nessa perspectiva, ambientes sérios e pouco acolhedores consistem em fatores determinantes para o estresse da criança, tornando-as menos receptiva aos cuidados ${ }^{(12)}$. Segundo relatos de familiares de pacientes, estudo $^{(15)}$ retrata que a realização de melhorias na infraestrutura hospitalar a fim de proporcionar mais privacidade $\mathrm{e}$ conforto durante o processo de internação na instituição, constitui-se numa possibilidade para que ocorra um atendimento humanizado e digno.

Em contrapartida, autores ${ }^{(13)}$ afirmam que o fator das condições 
físicas da unidade e poucos recursos materiais não são fatores determinantes para concretizar ou não o processo de humanização no local. Apesar de todas as dificuldades enfrentadas pelos profissionais isso não impediu que eles organizassem formas alternativas para amenizar o sofrimento das crianças, uma vez que a facilitação desse processo torna-se efetivo quando há o envolvimento da comunidade e da família.

Outro fator relatado por pesquisadores $^{(12)}$ refere-se à dificuldade em lidar com a família do paciente, pois pode ser um fator importante para $\mathrm{o}$ déficit na comunicação entre pais e profissionais, sendo que a própria jornada de trabalho submetida pelos profissionais impede a concretização da humanização. $\mathrm{O}$ autor ainda enfatiza que a incompreensão e a falta de colaboração dos familiares em relação aos cuidados oferecidos dificultam ainda mais o atendimento humanizado. No entanto, esta dificuldade se justifica pela ansiedade e alto nível de estresse presentes nos membros da família causados pela doença e por possíveis problemas gerados durante a internação de seus filhos. Desta maneira, torna-se inquestionável que o paciente oncológico e seus familiares sofrem, não só um desgaste mental, mas também social atribuído a doença, o que complica o processo de internação hospitalar e gera momentos de ansiedade e estresse, os quais contribuem para o surgimento de fatores que limitam a prestação do cuidado humanizado.

Independentemente do cenário de atuação, do perfil do cliente ou da fase do processo saúde-doença, o cuidado de enfermagem deve contemplar a integralidade nas ações ${ }^{(14)}$.

Embora se tenha muitas dificuldades e desafios a serem sobrepostos na assistência ao paciente oncológico, a humanização do cuidado pode ser realizada mesmo em locais com precárias condições de trabalho, uma vez que são os próprios indivíduos que definem as estratégias para alcançá$\mathrm{la}^{(13)}$. Estes mesmos autores salientam que apesar da existência de dificuldades, seja pela área física ou pelas impossibilidades financeiras, os profissionais são produzem condições favoráveis para que se possa amenizar o sofrimento do paciente.

\section{3) Estratégias para o cuidado humanizado}

Nos dias atuais, apesar de haver programas governamentais que determine que a assistência seja de 
maneira humanizada, bem como o acolhimento pelos profissionais de nos sistemas de saúde, estudos ${ }^{(11)}$ mencionam que, devido à uma elevada procura de uma parcela da população por instituições de saúde para a realização de tratamentos antineoplásicos, acreditava-se que haveria uma modificação em suas respectivas posturas, no sentido de refletir sobre a maneira como estão sendo assistidos pelos profissionais da saúde. Este fato decorre da percepção pelos pacientes do atendimento mecanicista e tecnicista por parte dos profissionais nestas instituições.

E, segundo a pesquisa supracitada, o ato de cuidar perdeu a essência de seu significado, sendo que, para resgatá-lo, deve-se elaborar de forma ampla uma habilidade de reconhecer a pessoa como um ser integral. $\mathrm{O}$ cuidado precisa tornar-se uma atitude, um modo de pensar e agir reflexivos e não apenas como uma obrigação a se cumprir, contudo, o cuidar do outro é parte da natureza humana que deve ser resgatada. Ao se pensar nesse aspecto, a assistência aos pacientes oncológicos requer dos profissionais de saúde uma escuta atenta e um olhar mais refinado com relação ao cuidado humanizado, uma vez que, historicamente, o câncer é estigmatizante e sempre associado à dor, sofrimento e, até mesmo, à finitude da vida. Pois, como reportado por dois pesquisadores $^{(9)}$, estes pacientes exigem uma assistência diferenciada porque carregam junto com a neoplasia a incerteza do prognóstico, o medo de morrer, a depressão, ansiedade e, a vontade de seguir adiante. Portanto, compreender o impacto do câncer nos indivíduos é essencial para desenhar estratégias de cuidados ${ }^{(13)}$.

Estudo $^{(2)}$ aponta algumas estratégias para a assistência humanizada ao paciente oncológico e sua família, as quais se baseiam em atitudes que permitam a criação de espaços para que todos relatem seus sentimentos e que estes sejam valorizados, ou seja, dar vozes aos que sofrem, para que seja possível identificar prováveis áreas problemáticas; auxiliá-los a desvendar mecanismos de ajuda, que podem estar dentro ou fora da própria família; fornecer informações e esclarecer dúvidas; auxiliá-los na busca de resoluções de possíveis problemas relacionados ao tratamento; orientá-los para que decidam da melhor maneira o tratamento proposto e, elevar o desempenho de ações de auto-cuidado, de acordo com suas possibilidades. Entre as inúmeras ações de saúde 
necessárias para a melhoria do cuidado, os aspectos psicológicos, estão à disponibilidade, a ação de aceitação, de escuta e a criação e a manutenção de um ambiente terapêutico.

Outra estratégia encontrada pelos próprios pacientes, a fim de prestar um cuidado humanizado, foi que os profissionais não devem dar importância ao desfecho do tratamento, mas que proporcionem o máximo que estiver ao seu alcance enquanto profissional de saúde. $\mathrm{Na}$ área pediátrica, o brinquedo é apontado como um dispositivo que pode amenizar o sofrimento causado pela doença e pela ruptura do convívio social como familiares, amigos, objetos pessoais, animais de estimação, pois favorece a representação de sentimentos como o medo, as angústias, a saúde, a tensão( ${ }^{(13)}$.

Nesse processo, é responsabilidade dos profissionais de saúde colocar em questão os sentimentos, as angústias e seus princípios tendo como resultado uma relação de confiança entre o paciente e família e os profissionais, cuja base encontra-se no carinho e o respeito $^{(9)}$. Estes mesmos autores destacam que a comunicação deve ser considerada um dos elementos essenciais na ação de autonomia do ser humano para que se tenha um entendimento entre as pessoas. Outra questão refere-se ao avanço tecnológico, que além de ser uma grande conquista só é totalmente eficaz quando interligado com a humanização e a comunicação terapêutica obtendo desta maneira melhores resultados em um atendimento de qualidade e bem estar do paciente e da ciência. Além destes, a criatividade também é apontada como uma ferramenta que permite proporcionar um ambiente mais acolhedor e humano, quando há envolvimento de familiares e comunidade em determinadas situações $^{(13)}$.

Vale destacar que, não somente os pacientes oncológicos necessitam de cuidados, mas a equipe também é um ponto chave que deve ser observado e requer atenção por meio de cuidados especiais, os quais visam mantê-la unida e preparada para uma eventual situação inesperada, pois o cotidiano destes profissionais que atuam na área oncológica os expõem à diversas situações geradoras de conflitos como estresses, frequentes perdas por morte, acompanhamento e maior envolvimento com o problema vivido pelos familiares e suas tristezas, os quais geram um sentimento de impotência do profissional diante da doença que pode traduzir-se em revolta ou em abatimento ${ }^{(2)}$. 
Para facilitar a humanização é preciso compreender os pacientes em suas necessidades por meio do compromisso para a compreensão e cuidado, haverá uma abertura para que haja a tão esperada humanização na assistência $^{(9)}$. A família é a unidade primária do cuidado cuja assistência deve ser focada na família, no caso pediátrico a fim de facilita o tratamento. A inclusão da família no aspecto do cuidar amplia a capacita a enfermagem a atender melhor esta criança, de forma integral quebrando a barreira do tecnicismo $^{(12)}$.

Corrobora com esta informação o fato de que, pacientes e familiares, não almejam apenas o cuidado, mas também por manifestações de solidariedade para com seu ente querido e a si próprio no circulo hospitalar. Além da importância dos cuidados recebidos dos profissionais no que tange às suas necessidades emocionais, o aspecto físico com acomodações adequadas também foi considerado relevante para que estes possam desenvolver-se nesta espacialidade vivida ${ }^{(15)}$. Entretanto, o espaço físico adequado, suporte e infraestrutura não são suficientes se as práticas dos profissionais não são sensibilizadas pelo meio ${ }^{(13)}$.

A sistematização da assistência (SAE) também é destacada como uma estratégia para a humanização do cuidado, porque pode favorecer a utilização do tempo disponível para a assistência de forma adequada, com objetivação, qualificação e humanização das ações. Pois, conforme aponta pesquisa $^{(14)}$, o cuidado será pensado e organizado de forma a valorizar a disponibilidade de tempo do enfermeiro para ajudar os clientes a partir das relações empáticas estabelecidas, de competência técnica e, consequentemente, da capacidade de ser resolutivo.

\section{CONSIDERAÇÕES FINAIS}

Este estudo permitiu-nos perceber que a humanização da assistência é um fator de grande relevância no tratamento em oncologia. Quer seja a capacitação dos profissionais da área da saúde, quer seja a educação continuada sobre o cuidado humanizado são fatos transformadores e de uma necessidade latente para um atendimento efetivo e de qualidade aos pacientes portadores de câncer. Embora exista uma política sobre a humanização da assistência, na prática, mediante literatura abordada, verificamos que a humanização pela equipe de enfermagem ainda se concentra em determinadas áreas em detrimento de 
outras, tais como: cuidados paliativos, assistência à criança oncológica, ou seja, à grupos de indivíduos considerados vulneráveis.

Pensando nas mudanças que ocorrem na vida dos pacientes oncológicos e nas dificuldades por ora reportadas, a enfermagem tem um papel fundamental para que a assistência aos mesmos seja realizada com ética, respeito e humanidade, pois a empatia deve permear todo o cuidar.

Como vimos, cabe ao profissional proporcionar um cuidado de qualidade visando o paciente integralmente, como um ser que apresenta e expressão seus sentimentos, apresenta suas próprias crenças e toda uma história de vida, com seus medos e seus limites. Junto deste, vem também sua família, sua base de vida, que no momento encontrase em conflito ou até mesmo desestabilizada seja de ordem física, psicológica, econômica e espiritual devido à doença.

O que não se pode esquecer é que para a humanização acontecer, não depende apenas da boa vontade da equipe, mas também da aceitação do paciente e seus familiares. As pessoas podem levar um tempo até quebrarem a barreira que existe entre a doença e seus cuidadores. Por isso, deve-se trabalhar com este doente e seus familiares, pois se eles não compreenderem a dimensão do cuidado, a humanização pode não acontecer. Porém com força de vontade, respeito e amor ao próximo todas as barreiras podem ser transpostas, e assim surgir um atendimento de qualidade e de base humanística.

\section{REFERÊNCIAS}

1. Figueiredo NMA. Tecnologias e Técnicas em Saúde-Como e porque utilizá-las no cuidado de enfermagem. São Caetano do Sul, SP: Editora Difusão; 2004. 370p.

2. Costa CA, Lunardi Filho WD, Soares NV. Assistência Humanizada ao Cliente Oncológico: reflexões junto à equipe. Revista Brasileira de Enfermagem [online], Brasília. 2003 Mai/Jun; 56(3): 310-14. Disponível em: http://www.scielo.br/pdf/reben/v 56n3/a19v56n3.pdf. Acesso em: 02 jan. 2013.

3. Brasil. Ministério da Saúde. Instituto Nacional do Câncer. Ações de enfermagem para o controle do câncer: uma proposta de integração ensinoserviço. 3ed. Rio de Janeiro, RJ: INCA; 2008.

4. Brasil. Ministério da Saúde. Secretaria de Assistência à Saúde. Programa Nacional de Humanização da Assistência Hospitalar [Internet]. Brasília, DF: Ministério da Saúde; 2001 
[citado 08 ago. 2013].

Disponível em:

http://bvsms.saude.gov.br/bvs/p ublicacoes/pnhah01.pdf. (Série

C. Projetos, Programas e

Relatórios, n. 20).

5. Brasil. Ministério da Saúde. Secretaria-Executiva. Núcleo Técnico da Política Nacional de Humanização. HumanizaSUS:

Política Nacional de Humanização: a humanização como eixo norteador das práticas de atenção e gestão em todas as instâncias do SUS [Internet]. Brasília, DF: Ministério da Saúde; 2004. [citado 08 ago. 2013]. Disponível em: http://bvsms.saude.gov.br/bvs/p ublicacoes/humanizasus_2004.p df. (Série B. Textos Básicos de Saúde).

6. Costa SC, Figueiredo MRB, Schaurich D. Humanização em Unidade de Terapia Intensiva Adulto (UTI): compreenções da equipe de enfermagem. Interface (Botucatu) [online]. 2009;

13(Suppl 1): S571-80.

Disponível em: http://www.scielo.br/scielo.php? pid=S1414$32832009000500009 \&$ script $=$ sci _arttext. Acesso em: 27 out. 2011.

7. Rother ET. Revisão sistemática $\mathrm{X}$ revisão narrativa [Editorial]. Acta Paulista de Enfermagem [online], São Paulo. 2007 Jun; 20(2).

Disponível em: http://www.scielo.br/pdf/ape/v2 0n2/a01v20n2.pdf. Acesso em: 25 jul. 2013.

8. Gomes IP, Reis PED, Collet N. Management of nursing's care in pediatric ambulatory chemotherapy unit. Revista de Enfermagem UFPE online, Recife. 2010 Abr/Jun; 4(2): 51016. Disponível em: http://www.revista.ufpe.br/revist aenfermagem/index.php/revista/ article/viewArticle/646. Acesso em: 07 ago. 2013.

9. Brito NTG, Carvalho R. A humanização segundo pacientes oncológicos com longo período de internação. Einstein [online], São Paulo. 2010; 8(2): 221-27. Disponível em: http://apps.einstein.br/revista/arq uivos/PDF/1369-

Einstein_v8n2_p221-7.pdf. Acesso em: 07 ago. 2013.

10. Rocha SMM, Almeida MCP. O processo de trabalho da enfermagem em saúde coletiva e a interdisciplinaridade. Rev. Latino-Am. Enfermagem [online], Ribeirão Preto. 2000 Dez; 8(6): 96-101. Disponível em:

http://www.scielo.br/pdf/rlae/v8 n6/12354.pdf. Acesso em: 17 set. 2013.

11. Siqueira KM, Barbosa MA, Boemer MR. O vivenciar a situação de ser com câncer: alguns des-velamentos. Rev Latino-am Enfermagem [online], Ribeirão Preto. 2007 Jul/Ago; 15(4). Disponível em: http://www.scielo.br/pdf/rlae/v1 5n4/pt_v15n4a13.pdf. Acesso em 06 ago. 2013. 
12. Maranhão TA, Melo BMS, Vieira TS, Veloso AMMV, Batista NNLAL. A humanização no cuidar da criança portadora de câncer: fatores limitantes e facilitadores. Journal of the Health Sciences Institute [Internet], São Paulo. 2011; 29(2): 106-09. Disponível em: http://www.unip.br/comunicacao /publicacoes/ics/edicoes/2011/02 _abr-jun/V29_n2_2011_p106109.pdf. Acesso em: 07 ago. 2013.

13. Duarte MLC, Noro A. Humanização: uma leitura a partir da compreensão dos profissionais da enfermagem. Revista Gaúcha de Enfermagem [Internet], Porto Alegre. 2010 Dez; 31(4): 685-92. Disponível em:

http://www.scielo.br/pdf/rgenf/v 31n4/a11v31n4.pdf. Acesso em 07 ago. 2013.

14. Silva MM, Moreira M. C. Desafios à sistematização da assistência de enfermagem em cuidados paliativos oncológicos: uma perspectiva da complexidade. Revista Eletrônica de Enfermagem [Internet], Goiânia. 2010; 12(3): 483-90. Disponível em: http://www.fen.ufg.br/revista/v1 2/n3/v12n3a10.htm. Acesso em: 07 ago. 2013.

\section{Sales CA, Grossi ACM,} Almeida CSL, Silva JDD, Marcon SS. Cuidado de enfermagem oncológico na ótica do cuidador familiar no contexto hospitalar. Acta Paulista de Enfermagem [Internet], São Paulo. 2012; 25(5): 736-42. Disponível em: http://www.scielo.br/pdf/ape/v2 5n5/14.pdf. Acesso em: 07 ago. 2013.
Sources of funding: No

Conflict of interest: No

Date of first submission: 2015-03-20

Last received: 2015-03-20

Accepted: 2015-03-23

Publishing: 2015-06-30

\section{Corresponding Address}

Av. Júlio Xavier da Silva, $n^{\circ} 73$, Bairro Parque Cidade Nova, Mogi-Guaçu/SP, Brasil Tel: +55 19 99618-1166.

\footnotetext{
'Artigo elaborado a partir do Trabalho de Conclusão de Curso (TCC) de Especialização em Oncologia pelo Instituto ENAF - FMG, Poços de Caldas/MG, Brasil.
} 